\title{
EVALUATING LANDSLIDE SUSCEPTIBILITY USING ENVIRONMENTAL FACTORS, FUZZY MEMBERSHIP FUNCTIONS AND GIS
}

\author{
A. GEMITZI ${ }^{1}$ \\ G. FALALAKIS ${ }^{2, *}$ \\ P. ESKIOGLOU ${ }^{3}$ \\ C. PETALAS ${ }^{1}$
}

\author{
${ }^{1}$ Department of Environmental Engineering, \\ Faculty of Engineering, Democritus University of Thrace, \\ 67100 Xanthi, Greece \\ ${ }^{2}$ Decentralized Administration of Macedonia and Thrace, \\ 69100 Komotini, Greece \\ ${ }^{3}$ Faculty of Forestry and Natural Environment \\ Aristotle University of Thessaloniki, 54124 Thessaloniki, Greece
}

Received: 09/06/10

Accepted: 22/12/10

\section{ABSTRACT}

A methodology for landslide susceptibility assessment to delineate landslide prone areas is presented using factor analysis and fuzzy membership functions and Geographic Information Systems (GIS). A landslide inventory of 51 landslides was created in the mountainous part of Xanthi prefecture (North Greece) and the associated conditioning factors were determined for each landslide by field work. Six conditioning factors were evaluated: slope angle, slope aspect, land use, geology, distance to faults and topographical elevation. Fuzzy membership functions were defined for each factor using the landslide frequency data. Factor analysis provided weights (i.e., importance for landslide occurrences) for each one of the above conditioning factors, indicating the most important factors as geology and slope angle. An overlay and index method was adopted to produce the landslide susceptibility map. In this map $96 \%$ of the observed landslides are located in very high and high susceptibility zones, indicating a suitable approach for landslide susceptibility mapping.

KEYWORDS: landslide susceptibility, conditioning factors, factor analysis, fuzzy membership functions.

\section{INTRODUCTION}

Landslides cause adverse effects on human lives and economy worldwide. As the urbanization is rapidly growing, the evaluation of landslide susceptibility is perceived nowadays as the initial stage in mitigating landslide hazards. There is a growing interest worldwide in developing robust methods for landslide susceptibility and risk mapping, and hence provide planners with tools for selecting suitable areas for development.

Traditionally, landslide susceptibility was determined using the physical laws that cause slope instability. As it is now well understood that landslides are a physical phenomenon that is controlled by various parameters, researchers have developed statistical methods for the estimation of landslide occurrence, examining various environmental factors such as topography, land uses, geology and hydrology.

Guzzetti et al. (1999) indicated the four basic principles that all methods of landslide investigation are based on, according to which a territory can be zoned into hazard classes ranked according to different probabilities.

Clerici et al. (2006) distinguished three distinct categories of methods for landslide susceptibility zonation: the deterministic (or engineering, or geotechnical), the heuristic (or index) and the statistical methods. The deterministic models rely upon the understanding of the physical laws controlling slope instability (Okimura and Kawatani, 1987; Dunne, 1991; Montgomery and Dietrich, 1994; Dietrich et al., 1995; Terlien et al., 1995). These models couple shallow subsurface flow, i.e., the pore pressure spatial distribution, with predicted soil thickness in order to model the landsliding 
of the soil mantle (Dietrich et al., 1995). Ercanoglou and Gokceoglou (2004) mention that deterministic approaches can be used for the small and relatively homogenous areas, and require detailed geotechnical and hydrogeological data and oversimplifications have to be made in order to apply such techniques in regional and medium scales.

In the heuristic methods, the instability factors are ranked and weighted according to their assumed or expected importance in causing slope failures. As the ranking and weighting rules are based on the experience of geoscientists involved, this approach entails a substantial degree of subjectivity.

The statistical methods are more objective and better suited for assessing landsliding probability, especially at medium scales. All the statistical methods, despite the methodological and operational differences, are based on the common assumption that slope failure in the future will be more likely to occur under those conditions which led to past and present instability (Clerici et al., 2006). Thus, the combination of parameters that have led to landslides in the past are determined statistically, and quantitative predictions are made for areas currently free of landslides but where similar conditions exist (Soeters and Van Westen, 1996).

Much research is focused and published on the preparation of hazard maps based on statistical modeling (Chau et al., 2004) or on ranking and weighting environmental factors according to their assumed or expected importance in causing slope failures (Chung et al., 2002; Dai and Lee, 2002; Dai et al., 2002; Donati and Turrini, 2002; Zhou et al., 2002; Fernandez et al., 2003; Lee and Choi, 2004, Ercanoglou et al., 2004).

Recently, new techniques such as fuzzy logic and neural networks have also been successfully applied in various environmental problems (Gemitzi et al., 2006; 2007; 2008; Papadopoulos et al., 2007). Some applications also include evaluation of landslide susceptibility (Ercanoglou and Gokceoglou, 2002; 2004; Lee et al., 2004; Kanungo et al., 2006, Caniani et al., 2008). The attractiveness of these techniques is that they investigate the nonlinearities and uncertainties of the considered system to solve the problem similarly to the human brain reasoning. The spatial data management and manipulation can be performed through Geographic Information Systems (GIS) (Dai and Lee, 2002; Sarkar and Kanungo, 2004; Chau et al., 2004; Clerici A., 2006).

The present study combines heuristic methods, i.e., ranking and weighting environmental factors, with statistical methods, aiming at minimizing the subjectivity in the weight assignment process. The concept of membership value for landslide susceptibility is used, as introduced by Ercanoglou and Gokceoglou (2004). A problem, usually encountered in multivariate studies, is that each conditioning factor is expressed in a different way, i.e., some factors are expressed in linguistic form whereas some others are in numerical form; some are categorical data whereas some others are nominal data. Moreover, different ways are used for data collection, i.e., some factors were measured directly, whereas some others are derived information. In this context, the use of membership degree for factor quantification and standardization seems quite convenient.

The methodology includes six steps: (1) the preparation of a landslide inventory of the study area based on field studies and data from previous works; (2) the identification of conditioning factors and the determination of their landslide frequencies; (3) the fuzzification of conditioning factors; (4) the application of multivariate statistical analysis (factor analysis) to determine the weights of the parameters; (5) the use of geographic information systems to produce the factor maps and the susceptibility map; and (6) the testing of reliability of the susceptibility map produced in a part of Hellenides, in Xanthi area (North Greece).

\section{STUDY AREA DESCRIPTION}

The methodology has been applied using data from shallow landslides of the mountainous part of Xanthi area (Thrace, Greece) (Figure 1). The study area covers approximately $850 \mathrm{~km}^{2}$ and it is bounded to the north from the Greek-Boulgarian border and extends to the south up to the Neogene Thrace basin.

The geological and geomorphological characteristics of the area are described in previous works (Kilias et al., 1999; Dinter and Royden, 1993). The geological structure consists of rock formations attributed to the Paleozoic Rhodope massif that include the marble unit (marbles and schists) and the gneissic unit (migmatites, gneisses, marble-amphibolite intercalations and ultra mafic rocks), and to the Tertiary mollasic and igneous rocks (Figure 2). 


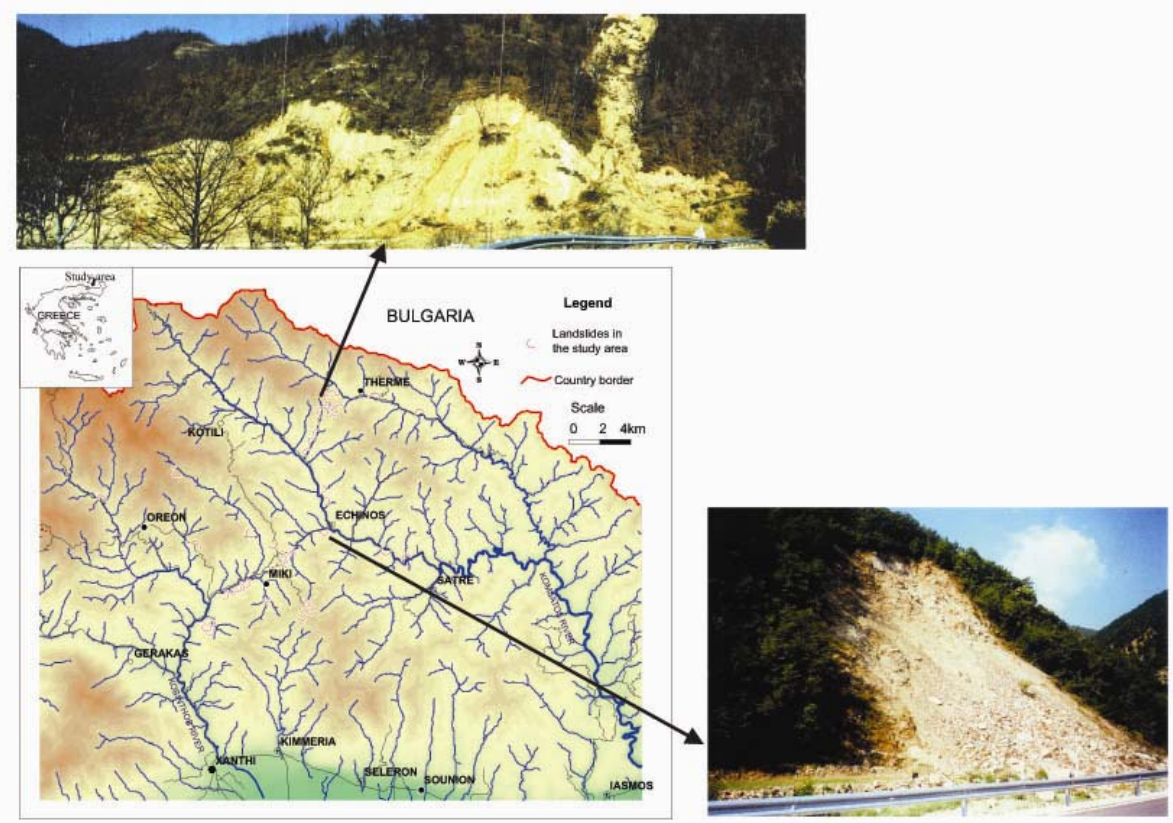

Figure 1. Geographical setting and landslide inventory map of the study area. Examples of mapped landslides

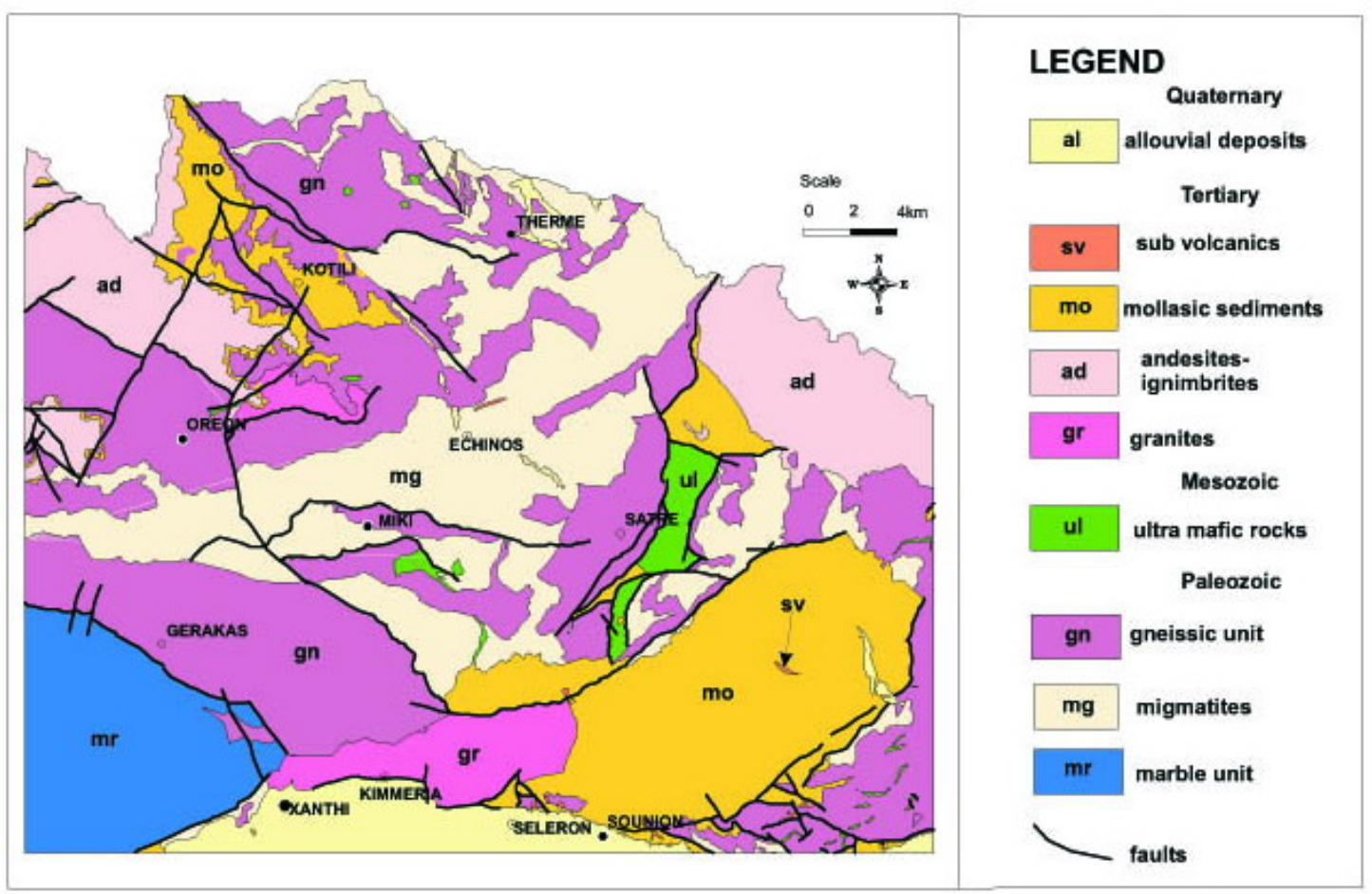

Figure 2. Geological map of the study area

These rocks were reactivated during Tertiary times resulting to the uplifting of the area. From the field survey most of the landslides were identified in the weathering zone of migmatite rocks. The area has a mountainous character. The topographical elevation values vary between 30 and $1800 \mathrm{~m}$ and the dominant drainage pattern is dendritic. The general physiographic trend is NW-SE following the main drainage system. Two major rivers flow through the study area in a NW-SE direction, i.e., Kosinthos river and Komsatos river (Figure 1). In addition, there are many subsidiary intermittent streams forming a very dense hydrographic network. From a climatic point of view, this part of the Rhodope mountain chain receives a mean annual rainfall of about $930 \mathrm{~mm}$, mainly concentrated during the winter (llias et al., 2000). Rainfall is observed mainly as sporadic storm events that trigger 
landslides in the region. The study area is mainly covered by dense and sparse forest whereas smaller parts are utilized for agricultural and pasture and residential purposes.

\section{DATA USED AND PROCESSING OF CONDITIONING FACTORS}

For a landslide susceptibility assessment, several parameters introduced in a GIS, as spatial data layers are necessary to evaluate the zones susceptible to sliding. When applying any model to landslide susceptibility evaluation, it is very important to define criteria controlling the degrees of susceptibility. Although any parameter may be important with respect to the landslide occurrence in a region, the same parameter may not be important for another region. Hence, different parameters are used and ranked subjectively or objectively to produce a landslide susceptibility map (Ercanoglu and Gokceoglu, 2004) by various researchers, according to the study area.

In the present study six conditioning factors were evaluated based on field work and on literature, i.e., slope angle, geology, distance to faults, topographical elevation, land use, slope aspect. A landslide inventory was created based on data collected by the present research work, as well as from previous studies (llias et al., 2000), thus 51 landslides were identified and the associated conditioning factors were determined for each landslide by field survey. During field work the dimensions of landslides were determined, which varied from $350 \mathrm{~m}^{2}$ to $15000 \mathrm{~m}^{2}$. The majority of landslides however have aerial extent of $600 \mathrm{~m}^{2}$ to $2500 \mathrm{~m}^{2}$. For each landslide the conditioning factors slope angle, topographical elevation (mean value of the highest and the lowest point of each landslide), slope aspect and land use were determined in the field. Moreover, using the 1:50,000 geological map produced by the Greek Geological and Mineral Exploration Service (llias et al., 2000) as a base map, a 1: 25,000 geological map was prepared during the present research work, by field work. Major fault features were mapped at this scale and were incorporated in the associated layer. Most of the landslides are observed as falls, whereas some have a circular mode of failure (Figure 1).

All landslides were introduced as vector polygons in the GIS program Idrisi Andes and the associated layer was then rasterized using a pixel size of $20 \mathrm{~m}$. Thus a total of 2063 pixels corresponding to landslides were produced, thus providing a sufficient number of points for statistical analysis to be performed. The pixel size of $20 \mathrm{~m}$ was determined based on the fact that the positional accuracy needed for 1:25,000 scale maps must be $\pm 12.5 \mathrm{~m}$ (Akgun and Bulut, 2007). In order to produce the GIS layers for the conditioning factors slope angle and slope aspect, the Digital Elevation Model (DEM) of the study area was prepared, using again a pixel size of $20 \mathrm{~m}$. All geological formations were introduced as vector polygons within GIS and were then rasterized with a pixel of $20 \mathrm{~m}$, in order to produce the layer of the conditioning factor geology. Major faults were introduced as vector lines in the GIS and after delineating buffer zones around them, they were converted into a raster layer with the same pixel size, i.e., $20 \mathrm{~m}$ in order to enter the computational process. Land uses were digitized as vector polygons or vector lines (in cases of rivers and roads) and were converted to raster format with $20 \mathrm{~m}$ pixel size. All GIS computations were performed using the GIS program Idrisi Andes (Eastman, 2006)

\section{METHODS AND MATERIALS}

Fuzzy logic was introduced by Zadeh (1965) and its basic idea is to regard map objects as members of a set. Unlike the classical set theory, where an object belongs or not to a set if it has a membership value of 1 , or not 0 respectively, the fuzzy set theory, membership values may range between 0 and 1 reflecting the degree of certainty of membership.

In order to express the degree of membership for a given property of interest, fuzzy set theory introduced the idea of a membership functions. Their choice and their associated values are critical aspects, while performing fuzzy logic analysis. There is no rule upon which fuzzy membership values are assigned. Some researchers simply use their subjective judgement as shown by Bonham-Carter (1994) for mineral exploration, while others are based on statistical analysis of their data (Ercanoglu and Gokceoglu, 2002). Fuzzy membership values can be derived by various functions representing the reality such as J-shaped, Sigmoidal, Linear and user defined function (Eastman, 2006). In the present case and in order to reflect reality while choosing fuzzy membership functions, they were selected based on the shape of the landslide frequency diagrams. 
For each conditioning factor the landslide frequency diagram was created, i.e, a diagram showing the number of landslides observed in each of the various classes of every conditioning factor to the area occupied by each specified class. Subsequently, fuzzy membership functions were selected in order to quantify the conditioning factors to membership values of landslide susceptibility, ranging from 0 (low susceptibility) to 1 (high susceptibility). The shape and control points of the fuzzy membership function for each parameter were selected based on the landslide frequency diagrams. For this purpose the GIS program Idrisi Andes (Eastman, 2006) and its routine FUZZY was used. FUZZY evaluates the possibility that each pixel belongs to a fuzzy set by evaluating any of a series of fuzzy set membership functions. The software provides the possibility to use either Sigmoidal, Jshaped or Linear functions, which are controlled by four points ordered from low to high on the measurement scale, or user-defined membership functions. The first point marks the location where the membership function begins to rise above 0 . The second point indicates where it reaches 1 . The third point indicates the location where the membership grade begins to drop again below 1, while the fourth point marks where it returns to 0 . Points may be duplicated to create monotonic or symmetric functions. The user-defined function requires the input of control points and their corresponding fuzzy set memberships. These pairs serve to define the shape of the fuzzy set membership curve (Eastman, 2006). Output is scaled from 0-1. This closed interval $[0,1]$ provides standardization for each factor. In the present study, the shape of the frequency diagrams indicates that a sigmoidal function may be applied for the parameters slope angle and topographical elevation. For categorical parameters, such as land use, geology, distance to faults, as well as for slope aspect, user-defined membership functions were applied. The membership functions for each one of the individual parameters examined are shown in the respective Figures $3-8$.

In order to define importance weights for each one of the conditioning factors, several approaches have been developed. Akgun and Bulut (2007) employed both logistic regression and Analytical Hierarchy Process in order to define importance weights, whereas Ercanoglu and Gokceoglu (2002) used factor analysis. In our case, factor analysis was used to produce the importance weights of the conditioning factors. As it is neither based on experts opinions nor on subjective judgements, factor analysis is supposed to be very objective, among the several multivariate analysis methods. Using the membership values, a correlation matrix was obtained. Factor analysis extracts the eigenvalues and eigenvectors of the correlation matrix, resulting in the determination of importance weights for each individual factor. All statistical calculations were carried out using the GIS software Idrisi Andes (Eastman, 2006).

\section{RESULTS}

\subsection{Conditioning factors \\ Geology}

The parameter "Geology" is related to the resistance to landslides. The most landslide sensitive formations are considered to be those with a mollasic character, i.e., sandstone, siltstone, marl alterations, due to different degree of weathering. Limestones and quartzites are considered to be resistant to landsliding formations, although this is highly dependent on various aspects such as erosion degree and structural fabric, which may alter the initial character of a geological formation. As mentioned earlier, the study area consists of a marble unit and a gneissic unit (migmatites, gneisses, amphibolites and ultra mafic rocks) of Paleozoic age, and of Tertiary mollasic and igneous rocks (Figure 2). The mollasic sediments outcrop alterations of unweathered sandstone and solid conglomerate. The frequency diagram for geology (Figure 3 ) demonstrates that the majority of landslides occurred within the migmatite formation. A user-defined fuzzy membership function $\left(\mu_{G}\right)$ was applied with the following control points: gneisses were assigned a membership value of 0.3 , the marble amphibolitic unit a value of 0.4 , migmatites a value of 1 , ultra mafic rocks were assigned a value of 0.2 , Quaternary sediments a value of 0.16 , and all other geological formations were assigned 0 (Figure 3 ). Thus the landslide susceptibility map based on geology was created (Figure 3). 

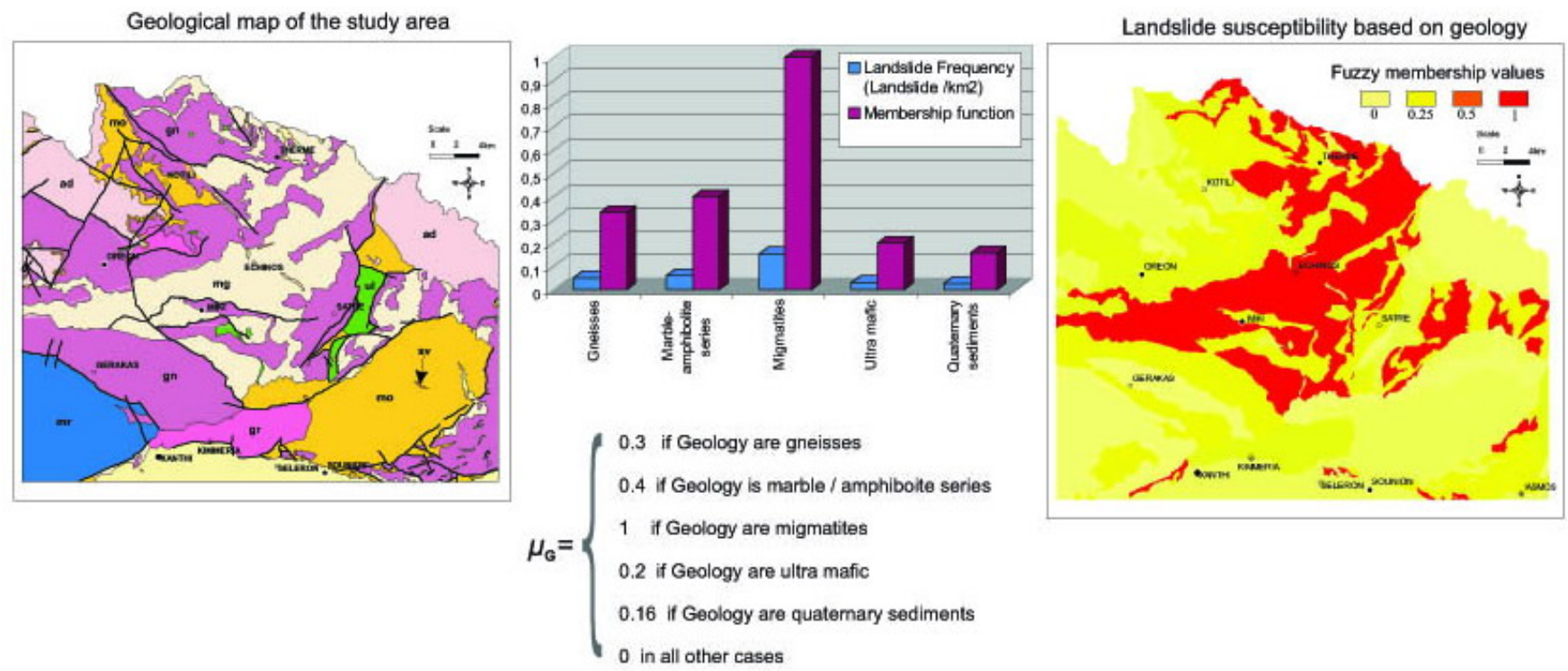

Figure 3. Derivation of the landslide susceptibility map based on geology

\section{Distance to faults}

Faults are the structural features which describe a zone of weakness with relative movement, along which landslide susceptibility is higher. It has generally been observed that the probability of landslide occurrence increases at sites close to faults, which not only affect the surface material structures but also make contribution to terrain permeability causing slope instability (Kanungo et al., 2006). The major fault features in the study area were mapped based on field work. During field survey, fault length, aspect, dip angle and type (normal, reverse, strike slip) were determined. Buffer zones of $250 \mathrm{~m}$ were generated around those features and the associated landslide frequencies were determined for the areas inside and outside those buffer zones (Figure 4). The frequency diagram indicated no significant difference between those two distinctive areas. A user-defined fuzzy membership function $\left(\mu_{F}\right)$ was applied with the following control points: 0.78 for the areas outside the $250 \mathrm{~m}$ fault buffer zones and 1 for the areas inside the $250 \mathrm{~m}$ fault buffer zones (Figure 4 ). Thus the landslide susceptibility map based on distance to faults was created (Figure 4).
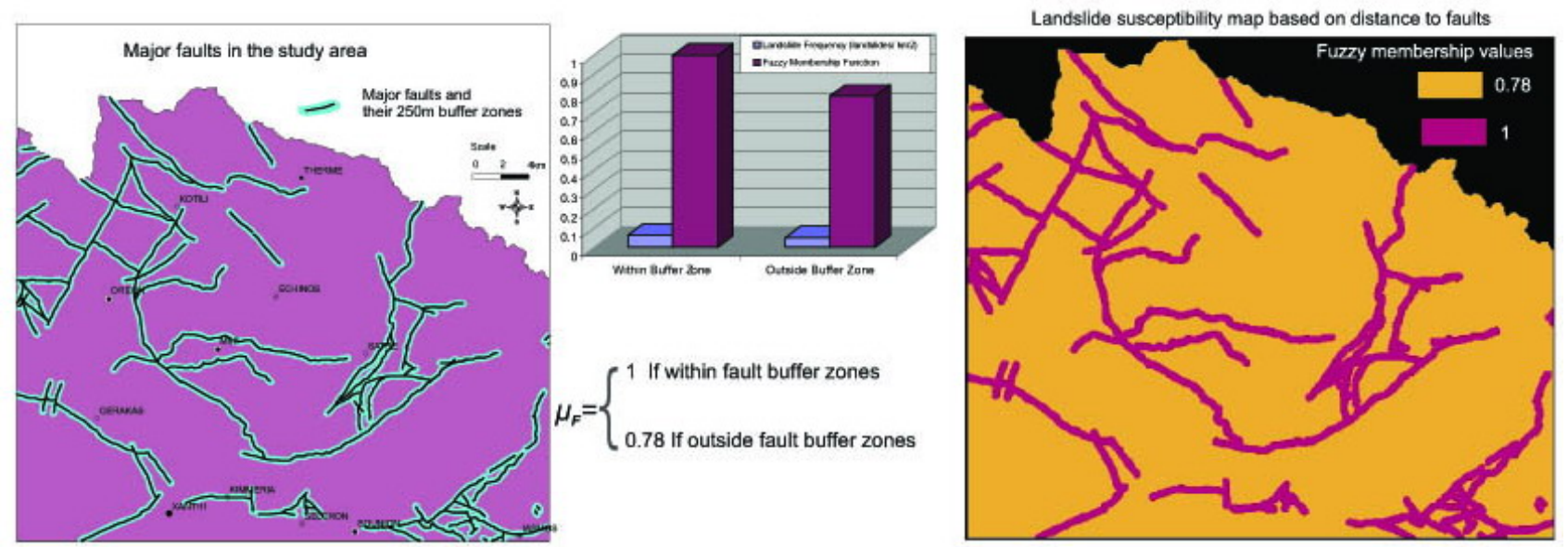

Figure 4. Derivation of the landslide susceptibility map based on distance to faults

\section{Slope angle}

For the "Slope angle" parameter, a symmetric sigmoidal fuzzy membership function $\left(\mu_{s}\right)$ was used with inflection points at $0^{\circ}$ (membership function begins to rise above 0 ), $30^{\circ}$ (membership function reaches 1 ), $40^{\circ}$ (membership grade begins to drop below 1 ) and $70^{\circ}$ (membership function returns to 0) (Figure 5). 

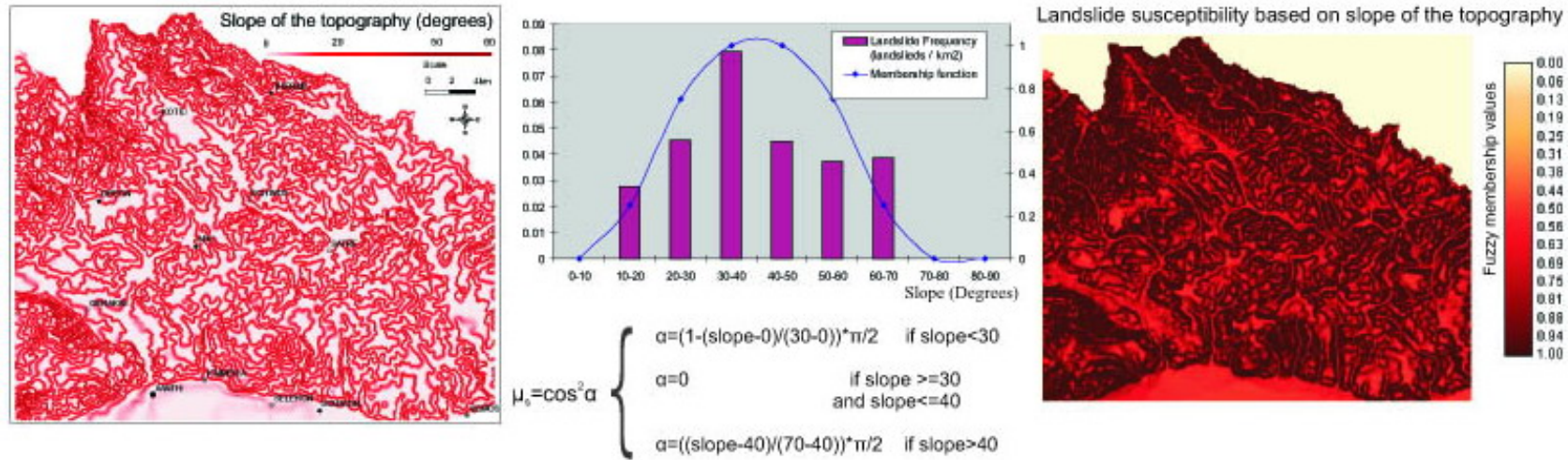

Figure 5. Derivation of landslide susceptibility map based on slope of the topography

As the frequency diagram for this specified factor indicates, when slopes exceed $50^{\circ}$, a sharp decrease in the landslide frequency values was observed, which has been determined by other researchers as well (Ercanoglu and Gokceoglu, 2002).

\section{Topographical elevation}

The frequency diagram for the parameter topographical elevation (Figure 6) indicates that it may be fuzzified using a symmetric membership function $\left(\mu_{A}\right)$ (Fig. 6) with inflection points at $200 \mathrm{~m}$ (membership function begins to rise above 0), $300 \mathrm{~m}$ (membership function reaches 1), $700 \mathrm{~m}$ (membership grade begins to drop below 1) and $900 \mathrm{~m}$ (membership function returns to 0 ). The frequency diagram for this factor (Fig. 6) shows that there is good agreement between landslide frequency and topographical elevations of $200-900 \mathrm{~m}$, whereas for elevations above $900 \mathrm{~m}$ the landslide frequency diminishes. In contrast to what is mentioned by Pachauri and Pant (1992), that the higher relief shows a greater susceptibility to sliding, Ercanoglu and Gokceoglu (2002) found a good agreement between landslide frequency and topographical elevations of 100-500 m, which is closer to the findings of the present study.

Topographical elevation

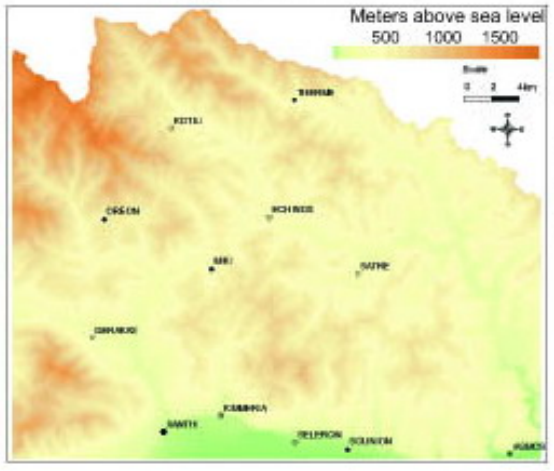

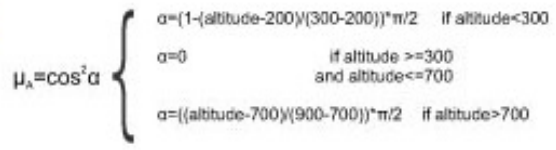

Landslide susceptibility based on topographic elevation

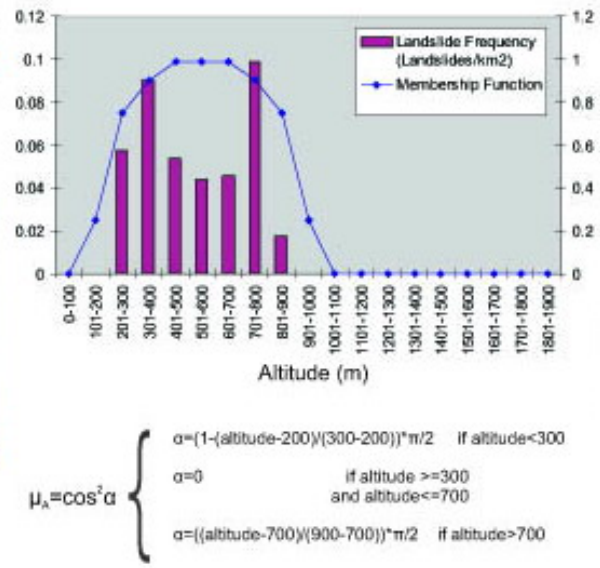

Figure 6. Derivation of landslide susceptibility map based on altitude

Slope aspect

Slope aspect (Figure 7) measures the direction that each grid cell faces in three-dimensional space and is recorded in azimuth degrees relative to true north. It is related to the general physiographic trend of the area and/or the main precipitation direction.

Although the relationship between landslide occurrence and slope aspect is still under investigation, some researchers (Carrara et al., 1991; Gokceoglu and Aksoy, 1996) introduce slope aspect in their computations, whereas others do not (Uromeihy and Mahdafivar, 2000). Ercanoglu and Gokceoglu (2002) found in their study area that the relationship between the dip direction of movement identified in the area and the general physiographic trend of the area were roughly perpendicular. In the present study, however, and as the frequency diagram for slope aspect indicates, no such relationship can be extracted. For this parameter a user defined fuzzy membership function $\left(\mu_{S A}\right)$ 
(Figure 7) was applied with appropriate control points to match the frequency diagram, whereas maximum membership, i.e. 1 , was assigned to aspect values between $150^{\circ}$ and $180^{\circ}$, and minimum membership, i.e. 0 , was assigned to aspect values between $210^{\circ}$ and $240^{\circ}$.
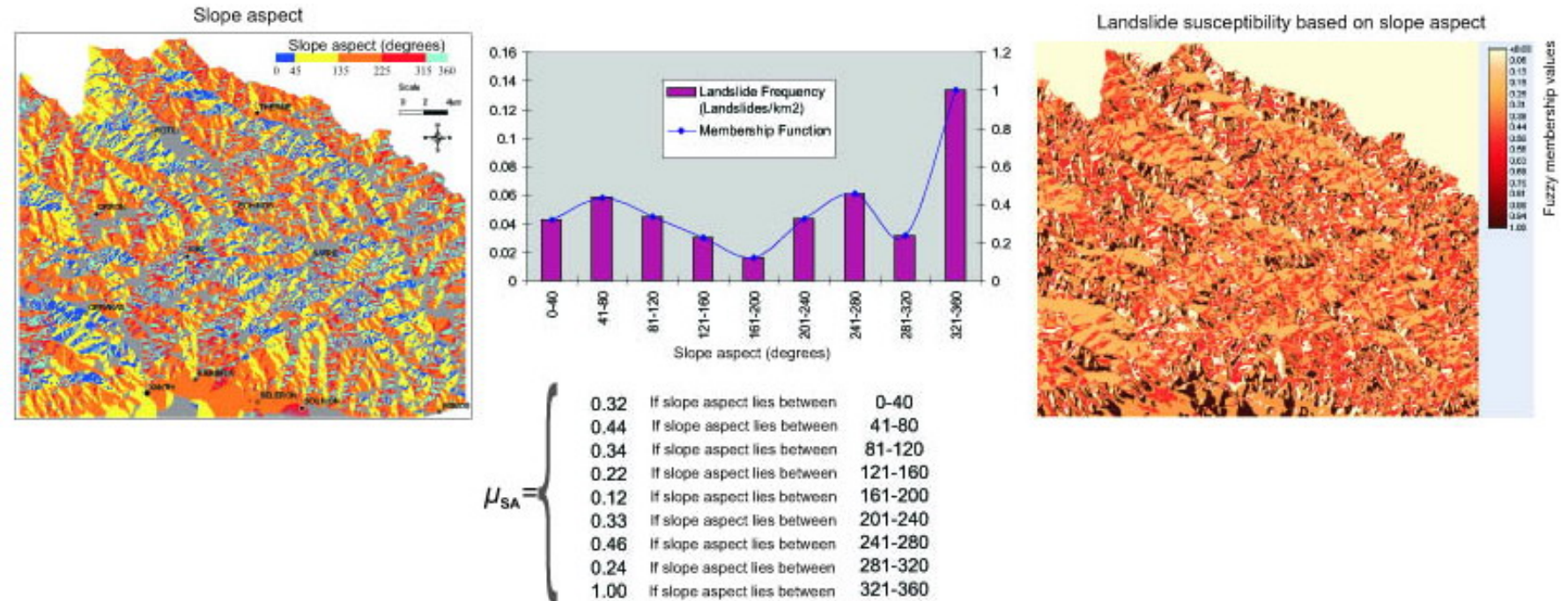

Figure 7. Derivation of landslide susceptibility map based on slope aspect

\section{Land use}

Land use (Figure 8) is the factor related to the effects caused by human activities on landslide occurrence. The study area is covered mainly by dense and sparse forests. To a lower extent grasslands and residential areas (mainly in the form of small settlements) occupy the study area. Moreover, zones of $20 \mathrm{~m}$ around roads and rivers were delineated and incorporated in the land use layer, which correspond to the adjacent to those features pixels, which are the ones that might have been influenced by the presence of rivers or the construction of roads. The frequency analysis (Figure 8) showed an indisputable negative effect of road construction on slope instability. A user defined fuzzy membership function $\left(\mu_{L U}\right)$ (Figure 8) was applied this time as well, with the following control points: dense forest was assigned a membership value of 0.20 , sparse forest a value of 0.36 , grassland a value of 0.27 , residential areas a value of 0.37 , roads a value of 1 (complete membership), 0 for water bodies (merely corresponding to the bodies of perennial rivers) and a value of 0.25 for river buffer zones.
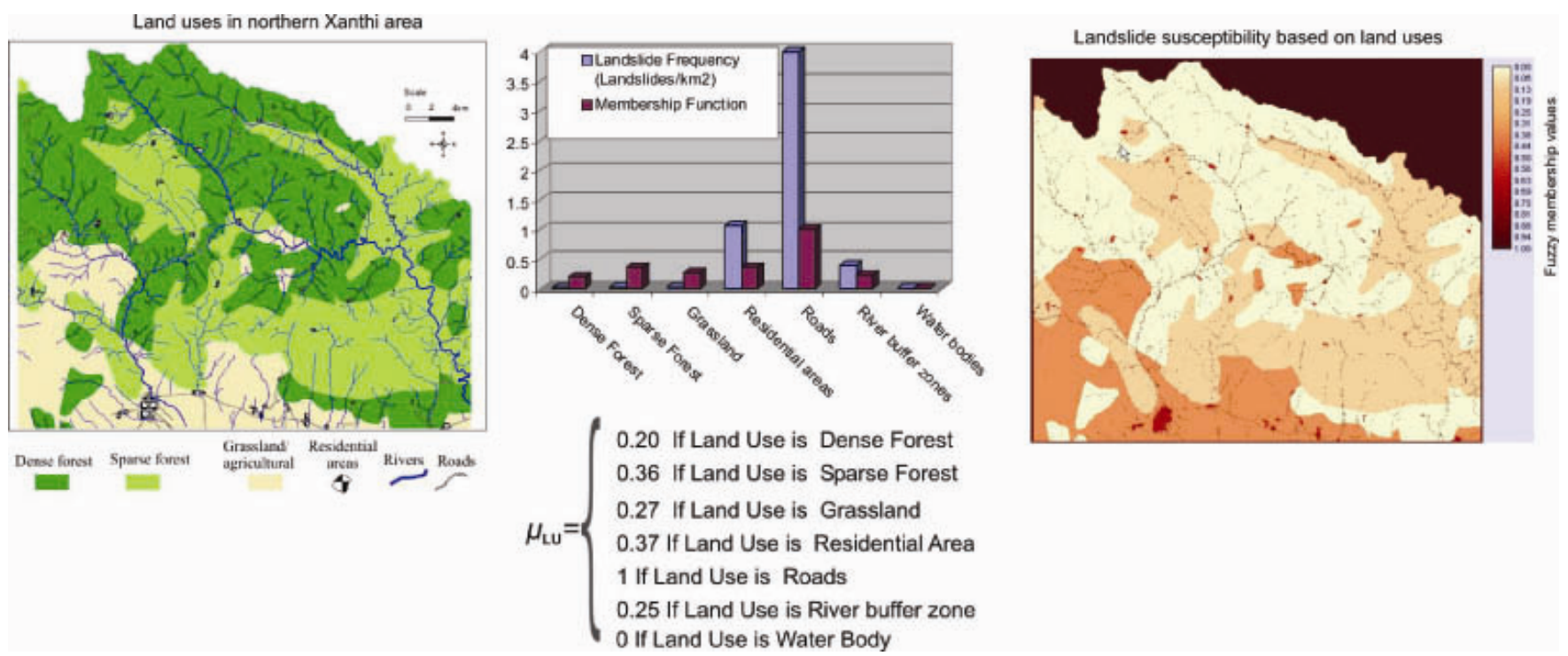

Figure 8. Derivation of landslide susceptibility map based on land uses 


\subsection{Factor analysis}

According to the results of factor analysis (Table 1), the importance weight for geology is the highest, and corresponds to $24.2 \%$ of the input variance. Slope angle is the second most important parameter, corresponding to $17.9 \%$ of the input variance. Furthermore, land use, distance to faults, elevation of the topography, and slope aspect are the third, fourth and fifth important parameters corresponding to $16.7 \%, 16.4 \%, 12.9 \%$ and $11.9 \%$ respectively, of the input variance. Thus, the membership function for landslide susceptibility was determined as:

$\left(\mu_{L S}\right)=\left(0.242 \times \mu_{G}\right)+\left(0.179 \times \mu_{S}\right)+\left(0.167 \times \mu_{L U}\right)+\left(0.164 \times \mu_{F}\right)+\left(0.129 \times \mu_{A}\right)++\left(0.11 \times \mu_{S A}\right)$

Table 1. Factor analysis results

\begin{tabular}{ccccccc}
\hline COMPONENT & C 1 & C 2 & C 3 & C 4 & C 5 & C 6 \\
\hline \% VARIANCE & 24.18 & 17.95 & 16.69 & 16.39 & 12.87 & 11.92 \\
\hline LOADING & C 1 & C 2 & C 3 & C 4 & C 5 & C 6 \\
\hline Distance to faults & 0.082 & -0.366 & 0.613 & 0.684 & 0.123 & -0.009 \\
\hline Geology & -0.641 & 0.445 & 0.078 & 0.148 & 0.183 & -0.574 \\
\hline Land use & 0.561 & 0.501 & 0.701 & -0.108 & -0.101 & 0.127 \\
\hline Elevation & -0.639 & 0.431 & 0.187 & 0.133 & 0.608 & 0.071 \\
\hline Aspect & 0.164 & 0.161 & 0.193 & 0.667 & 0.073 & 0.586 \\
\hline Slope & -0.533 & -0.531 & -0.236 & -0.139 & 0.582 & 0.143 \\
\hline
\end{tabular}

To obtain the landslide susceptibility map, the technique of overlaying of index maps was used. When overlaying the index maps, Equation (1) was used and the landslide susceptibility map was obtained for the study area (Figure 9a) with index values ranging from 0 (non-susceptible areas) to 1 (very high susceptibility to landsliding). After obtaining the landslide susceptibility map, the need to divide it into susceptibility classes appeared. In order to objectively select class boundaries, the method of success rate curves as defined by Kanungo et al.(2006), was adopted. The method is based on the determination of the mean $\left(\mu_{o}\right)$ and standard deviation $\left(\sigma_{o}\right)$ from the probability distribution curve of the landslide susceptibility map values. The mean value was defined to be 0.393 , whereas the standard deviation value was 0.202 . Thus, the boundaries for each one of the five susceptibility classes were defined as follows: $\left(\mu_{0}-1.5 m \sigma_{0}\right),\left(\mu_{0}-0.5 m \sigma_{0}\right),\left(\mu_{0}+0.5 m \sigma_{0}\right)$ and $\left(\mu_{\mathrm{o}}+1.5 m \sigma_{\circ}\right)$ where $m$ is a positive, non-zero value (Saha et al., 2005; Kanungo et al., 2006) which controls in fixing the most appropriate boundaries within the range of values of the landslide susceptibility map, for landslide susceptibility classes. In that way, the classes are defined statistically, without the need of subjectively dividing the map into classes, as it is always done in the conventional procedure. Five values of $\mathrm{m}$, i.e., $\mathrm{m}=0.8,1.0,1.1,1.2$ and 1.4 were used and the associated landslide susceptibility zones were defined. The corresponding landslide susceptibility maps were prepared and success rate curves (Kanungo et al., 2006) were plotted for each one (Figure $9 \mathrm{~b}$ ). Those curves are plots of the cumulative percentage of landslide occurrences in various susceptibility zones ordered from very high susceptibility to very low susceptibility against the cumulative percentage of area of the susceptibility zones for these landslide susceptibility zone maps. Success rate curve was also plotted for the equal interval method of landslide susceptibility zoning. According to Kanungo et al. (2006), the suitability of each of those maps can be judged by the fact that more percentage of landslides must occur in very high susceptibility zone as compared to other zones. It can be seen from Figure $9 \mathrm{~b}$ that for $10 \%$ of the area in the very high susceptibility zone, the curves corresponding to $m=0.8,1.0,1.1,1.2$ and 1.4 show landslide occurrences of $32 \%$, $31 \%, 30 \%, 28 \%$, and $17 \%$ respectively. The equal interval curve show landslide occurrence of $20 \%$, for the $10 \%$ of the area in the very high susceptibility zone, Thus, the curve corresponding to $m=0.8$ has the highest success rate and the associated landslide susceptibility map seems to be the most appropriate one for the study area. The results are also shown in tabular form in Table 2.

In order to validate the present methodology and control the performance of the produced susceptibility map, a comparison between the landslide susceptibility class zones on the map and the number of landslides observed in each class was carried out (Table 2), as it is usually done in related studies (Ercanoglu and Gokceoglu, 2002; Kanungo et al., 2006). Forty five landslides, i.e., $92 \%$ of the landslides, were observed in the very high zone, 3 landslides were observed in the high susceptibility zone and only 1 was located in the zone of moderate susceptibility. This high accuracy 
percentage indicates that the presented herein methodology offers a reliable approach for landslide susceptibility mapping.
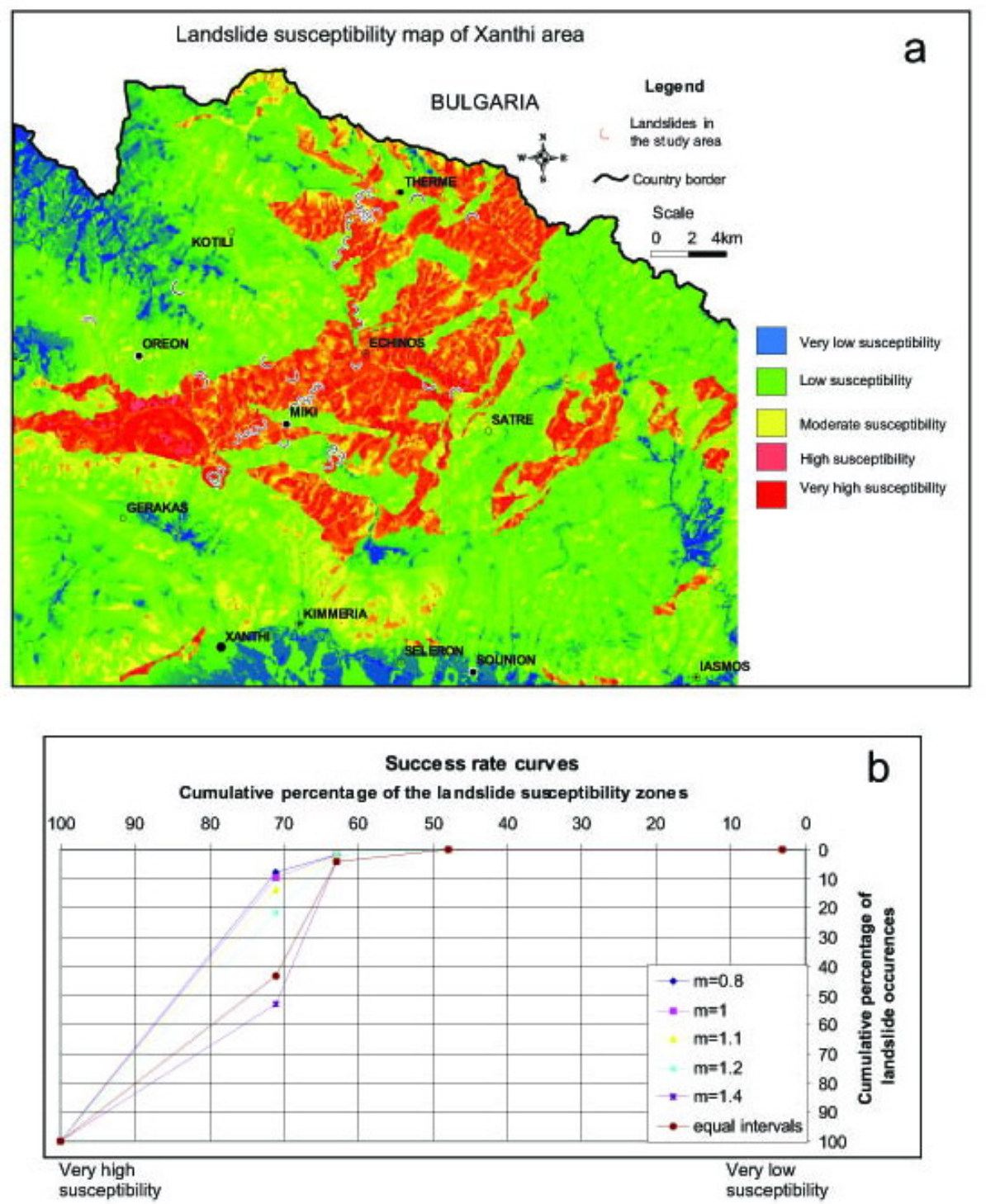

Figure 9. a) Landslide susceptibility map, b) Success rate curves

Table 2. Landslide susceptibility results

\begin{tabular}{cccc}
\hline Susceptibility Class & Index value & $\begin{array}{c}\text { Landslides } \\
\text { observed }\end{array}$ & \% of the study area \\
\hline Non-susceptible & $0-0.1506$ & 0 & 3 \\
Low susceptibility & $0.1506-0.3122$ & 0 & 45 \\
Moderate susceptibility & $0.3122-0.4738$ & 1 & 15 \\
High susceptibility & $0.4738-0.6354$ & 3 & 8 \\
Very high susceptibility & $0.6354-1$ & 47 & 29 \\
\hline
\end{tabular}

\section{DISCUSSION AND CONCLUSION}

Landslide susceptibility was assessed by examining various environmental factors using fuzzy membership functions and factor analysis. For this purpose, data obtained from previous surveys were combined with those obtained by field work carried out within the scope of present study. As a result, a landslide inventory was created for the study area, which comprised 51 landslides. Then, conditioning parameters were determined and for each parameter a landslide frequency diagram was created. Based on these frequency diagrams, fuzzy membership functions were determined, each parameter was fuzzified, and landslide susceptibility maps were constructed for each individual parameter. In order to determine the importance weight of each conditioning factor, factor analysis 
was applied in the form of the correlation matrix. Accordingly, the fuzzified index maps were aggregated in order to produce the final landslide susceptibility map for the northern Xanthi area.

According to the produced results, the landslides in the study area are merely controlled by geology, which is in agreement with the findings of other researchers elsewhere (Kamp et al., 2008). In contrast to the general belief that mollasic type formations favour landslide occurrences, the present work shows that in the study area the majority of landslides occurred within migmatite formations, whereas only a negligible percentage of landslides occurred within the molassic sediments. This indicates that although the type of geological formation might be an important conditioning factor, the degree of weathering and the structural fabric of each formation are responsible for its behaviour to landsliding.

The second most important parameter is slope. The observation that demonstrated a decrease of landslide frequency for slopes greater than $50^{\circ}$ seems quite peculiar. The same, however, is observed by other researchers such as Ercanoglu and Gokceoglu (2002). They attributed this observation to the fact that the steep slopes, in their area, are generally formed by hard limestones and quartzites, which are resistant to landsliding. In order to extract safe conclusions, however, those observations should be combined with geological data, especially with data related to dip angles of the geological strata.

Land use is the third most important factor determined by factor analysis, indicating the influence of human activities in the landslide occurrence. The majority of landslides in the study area occurred on road sides or in residential areas, indicating thus that they might have been prevented if proper design and construction methods were employed.

The fourth most important parameter was determined to be distance to faults. In the frequency analysis no major difference was observed between those areas within $250 \mathrm{~m}$ from major fault structures and those outside. This might be attributed the fact that there is no dense fault pattern to control the landsliding in the scale of mapping.

The fifth determined parameter is topographical elevation, with an importance weight of $12.5 \%$. Actually, those results are in agreement with the findings of Ercanoglu and Gokceoglu (2002), where they determined an importance weight for that factor of $12.5 \%$. In the present study there is good agreement between landslide frequency and topographical elevations of 200-900 m, whereas for elevations above $900 \mathrm{~m}$ the landslide frequency diminishes. Ercanoglu and Gokceoglu (2002) found a good agreement between landslide frequency and topographical elevations of $100-500 \mathrm{~m}$. The general observation, however that landslide frequency diminishes above a certain altitude, is the same in both cases.

No dominant physiographic direction was found to favour landslides, in contrast to what was previously mentioned by other researchers. In fact, factor analysis determined the least importance weight i.e., $11.9 \%$ for slope aspect.

The methodology demonstrated a success rate of $92 \%$, i.e., 45 out of 51 landslides, were observed in the very high susceptibility zone and therefore it is a reliable approach for landslide susceptibility mapping, providing a mathematical basis for expressing each conditioning factor, and combining numerical and categorical data in the computational procedure.

\section{REFERENCES}

Akgun A. and Bulut F. (2007), GIS-based landslide susceptibility for Arsin-Yomra (Trabzon, North Turkey) region, Environmental Geology, 51, 1377-1387.

Bonham-Carter G.F. (1994), Geographic Information Systems for Geoscientists, Modelling with GIS: Pergamon, Ottawa, $398 \mathrm{p}$.

Caniani D., Pascale S., Sdao F. and Sole A. (2008), Neural networks and landslide susceptibility: a case study of the urban area of Potenza, Natural Hazards, 45, 55-72.

Carrara A.M., Cardinali R., Detti F., Guzzetti V.P. and Reichenbach P. (1991), GIS techniques and statistical models in evaluating landslide hazard, Earth Surface Processes Landforms, 16, 427-445.

Chau K.T., Sze Y.L., Fung M.K., Wong W.Y., Fong E.L. and Chan, L. CP. (2004), Landslide hazard analysis for Hong Kong using landslide inventory and GIS, Computers Geosciences, 30, 429-443.

Chung C.F., Kojma H. and Fabbri A.G. (2002), Stability analysis of prediction models for landslide hazard mapping, In: Allison, R.J. (Ed.), Applied Geomorphology, Theory and Practice, 3-19. 
Clerici A., Perego S., Tellini C. and Vescovi P. (2006), A GIS-based automated procedure for landslide susceptibility mapping by the Conditional Analysis method: the Baganza valley case study (Italian Northern Apennines), Environmental Geology, 50, 941-961.

Dai F.C. and Lee C.F. (2002), Landslide characteristics and slope instability modelling using GIS, Lantau Island, Hong Kong, Geomorphology, 42, 213-228.

Dai F.C., Lee C.F. and Ngai Y.Y. (2002), Landslide risk assessment and management: an overview, Engineering Geology, 64, 65-87.

Dietrich E.W., Reiss R., Hsu M.L. and Montgomery D.R. (1995), A process-based model for colluvial soil depth and shallow landsliding using digital elevation data, Hydrological Processes, 9, 383-400.

Dinter D.A. and Royden L. (1993), Late Cenozoic extension in northeatern Greece: Strymon valley detachment system and Rhodope metamorphic core complex, Geology, 21, 45-48.

Donati L.and Turrini M.C. (2002), An objective method to rank the importance of the factors predisposing to landslides with the GIS methodology: application to an area of the Apennines (Valnerina; Perugia, Italy), Engineering Geology, 63, 277-289.

Dunne T. (1991), Stochastic aspects of the relations between climate, hydrology and landform evolution, Transaction Japanese Geomorphological Union, 12, 1-24.

Eastman (2006), IDRISI Andes Guide to GIS and Image Processing, Clark Labs, Clark University, USA.

Ercanoglu M. and Gokceoglu C. (2002), Assessment of landslide susceptibility for a landslide-prone area (North of Yenice, NW Turkey) by fuzzy approach, Environmental Geology, 41, 720-730.

Ercanoglu M. and Gokceoglu C. (2004), Use of fuzzy relations to produce landslide susceptibility map of a landslide prone area (West Black Sea Region, Turkey), Engineering Geology, 75, 229-250.

Ercanoglou M., Gokceoglou C. and Van Asch Th.W.J. (2004), Landslide susceptibility zoning north of Yenice (NM Turkey) by multivariate statistical techniques, Natural Hazards, 32, 1-23.

Fernandez T., Irigaray C., Hamdouni R.El. and Chaco J. (2003), Methodology for Landslide Susceptibility Mapping by means of a GIS. Application to the Contraviesa Area (Granada, Spain), Natural Hazards, 30, 297-308.

Gemitzi A., Petalas C., Tsihrintzis V.A. and Pisinaras V. (2006), Assessment of groundwater vulnerability to pollution: a combination of GIS, fuzzy logic and decision making techniques, Environmental Geology, 49, $653-673$.

Gemitzi A., Tsihrintzis V.A., Voudrias V., Petalas C. and Stravodimos G. (2007), Combining GIS, multicriteria evaluation techniques and fuzzy logic in siting MSW landfills, Environmental Geology, 51, 797-811.

Gemitzi A., Petalas C., Pisinaras V. and Tsihrintzis V.A. (2008), Spatial prediction of nitrate pollution in groundwaters using neural networks and GIS: An application to South Rhodope aquifer (Thrace, Greece), Hydrological Processes, 23, 372-383.

Gokceoglu C. and Aksoy H. (1996), Landslide susceptibility mapping of the slopes in the residual soils of the Mengen region (Turkey) by deterministic stability analyses and image processing techniques, Engineering Geology, 44, 147-161.

Guzzetti F., Carrara A., Cardinalli M. and Reichenbach P. (1999), Landslide hazard evaluation: a review of current techniques and their application in a multi-case study, central Italy, Geomorphology, 31, 181-216.

Ilias P., Rozos D., Konstandopoulou G., Dimadis E., Salapa E., Apostolidis E. and Gemitzi A. (2000), Engineering Geology Study of Disasterous Phenomena in Central Rhodope Mountain, Greek Institute of Geology and Mineral Exploration, Internal Report T-2117, (in Greek).

Kamp U., Growley B., Khattak G., Ghazanfar A. and Owen L. (2008), GIS-based landslide susceptibility mapping for the 2005 Kashmir earthquake region, Geomorphology, 101, 631-642.

Kanungo D.P., Arora M.K., Sarkar S. and Gupta R.P. (2006), A comparative study of conventional, ANN black box, fuzzy and combined neural and fuzzy weighting procedures for landslide susceptibility zonation in Darjeeling Himalayas, Engineering Geology, 85, 347-366.

Kilias A., Falalakis G. and Mountrakis D. (1999), Cretaceous-Tertiary structures and kinematics of the Serbomacedonian metamorphic rocks and their relation to the exhumation of the Hellenic hinterland (Macedonia, Greece), International Journal Earth Sciences, 88, 513-531.

Lee S. and Choi J. (2004), Landslide susceptibility mapping using GIS and the weight-of- evidence model, International Journal Geographical Information Science, 18, 789-814.

Lee S., Ryu J.H., Won J.S. and Park H.J. (2004), Determination and application of the weights for landslide susceptibility mapping using an artificial neural network, Engineering Geology, 71, 289- 302. 
Montgomery D.R. and Dietrich W.E. (1994), Landscape dissection and drainage area-slope thresholds. In Kirkby, M.J. (Editor), Process Models and Theoretical Geomorphology. British Geomorphological Research Group Symposia Series, John Wiley \& Sons Ltd.,Chichester, 221- 246.

Okimura T. and Kawatani T. (1987), Mapping of the potential surface- failure sites on granite slopes. In Gardiner, E. (Ed.), International Geomorphology 1986 Part I., Wiley, Chichester, 121-138

Pachauri A.K. and Pant M. (1992), Landslide hazard mapping based on geological attributes, Engineering Geology, 32, 81-100.

Papadopoulos B., Tsagarakis K.P. and Yannopoulos A., 2007, Cost and Land Functions for Wastewater Treatment Projects: Typical Simple Linear Regression versus Fuzzy Linear Regression, Journal of Environmental Engineering, 133, 581-586.

Saha A.K., Gupta R.P., Sarkar S., Arora M.K. and Csaplovics E. (2005), An approach for GIS-based statistical landslide susceptibility zonation-with a case study in the Himalayas, Landslides, 2, 61-69.

Sarkar S. and Kanungo D.P (2004), An intergraded approach for landslide susceptibility mapping using remote sensing and GIS, Photogrammetric Engineering and Remote Sensing, 70(5), 617-625.

Soeters R.S. and Van Westen C.J. (1996), Slope instability recognition, analysis and zonation. In: Turner, A.K., Schuster, R.L. (Eds.), Landslides: Investigation and Mitigation. Transportation Research Board, Special Report, Vol. 247. National Academy Press, Washington, DC, 129- 177.

Terlien M.TJ., Van Asch Th.WJ. and Van Westen C.J. (1995), Deterministic modelling in GIS-based landslide hazard assessment. In: Carrar, A., Guzzetti, F. (Editors.), Geographical Information Systems in Assessing Natural Hazards. Kluwer, London, 57- 77.

Uromeihy A. and Mahdafivar M.R. (2000), Landslide hazard zonation of Khorshrostam area, Iran, Bulletin of Engineering Geology and the Environment, 58, 207-213.

Zadeh L.A. (1965), Fuzzy sets, IEEE Information and Control, 8, 125-151.

Zhou C.H., Lee C.F., Li J. and Xu Z.W. (2002), On the spatial relationship between landslides and causative factors on Lantau Island, Hong Kong, Geomorphology, 43, 197-207. 